\title{
Synthesis of Na-Doped Lithium Metatitanate and Its Absorption for Carbon Dioxide
}

\author{
Liu Zhirong, ${ }^{1,2}$ Zhang Huan, ${ }^{2}$ Wang Yun, ${ }^{2}$ and Zhan Xinxing ${ }^{2}$ \\ ${ }^{1}$ Key Laboratory of Nuclear Resources and Environment, East China Institute of Technology, Ministry of Education, \\ Jiangxi 330013, China \\ ${ }^{2}$ Department of Applied Chemistry, East China Institute of Technology, Jiangxi 344000, China
}

Correspondence should be addressed to Liu Zhirong; zhrliu@ecit.cn

Received 3 January 2014; Revised 10 March 2014; Accepted 17 March 2014; Published 22 April 2014

Academic Editor: Shafiul Chowdhury

Copyright (C) 2014 Liu Zhirong et al. This is an open access article distributed under the Creative Commons Attribution License, which permits unrestricted use, distribution, and reproduction in any medium, provided the original work is properly cited.

\begin{abstract}
Na-doped lithium metatitanate $\left(\mathrm{Na}\right.$-doped $\left.\mathrm{Li}_{2} \mathrm{TiO}_{3}\right)$ absorbent was doped with $\mathrm{Na}_{2} \mathrm{CO}_{3}$ and lithium metatitanate $\left(\mathrm{Li}_{2} \mathrm{TiO}_{3}\right)$ was prepared by a solid-state reaction method from mixture of $\mathrm{TiO}_{2}$ and $\mathrm{Li}_{2} \mathrm{CO}_{3}$. The $\mathrm{Na}$-doped lithium metatitanate was characterized by X-ray diffraction (XRD) and scanning electron microscopy (SEM) and surface area. Carbon dioxide absorption on Na-doped lithium metatitanate was investigated using TG-DTA. The results reveal an increase of the $\mathrm{CO}_{2}$ absorption capacity of the Na-doped materials with respect to pure $\mathrm{Li}_{2} \mathrm{TiO}_{3}$. XRD patterns of the doped samples suggest a limited substitution of $\mathrm{Li}$ by $\mathrm{Na}$ atoms within the $\mathrm{Li}_{2} \mathrm{TiO}_{3}$ structure. The results of experimental and modeling work were summarized to better understand the relationship between the sorbent microstructure and carbon dioxide absorption kinetics.
\end{abstract}

\section{Introduction}

Carbon dioxide is the largest contributor among greenhouse gases (GHS) in regard to its amount in the atmosphere. The explosive increase in energy consumption of fossil-fuels by the rapid increase of population resulted in an accumulation of anthropogenic carbon dioxide in the atmosphere. By the year 2100, the atmosphere may contain up around $570 \mathrm{ppmv}$ carbon dioxide against 270 ppmv carbon dioxide before the industrial revolution. Carbon dioxide is causing a rise of mean global temperature of around $1.9^{\circ} \mathrm{C}$ and an increase of mean sea level of $38 \mathrm{~m}$ [1]. Fossil-fuel power plants are responsible for roughly 40 percent of total carbon dioxide emissions; hence it is important to capture carbon dioxide from coal-fired power plants in order to maintain the threshold value limit in the atmosphere and avoid any catastrophic effects.

Many researchers are working on the reduction of carbon dioxide emissions using various approaches since the Kyoto protocol was adopted at COP 3 in Japan [2-14]. Current technologies being considered for carbon dioxide capture include absorption, adsorption, membrane process, and disposal of carbon dioxide in deep oceans. If absorption is considered to be an economically viable technology for the carbonation reaction efficiency from combustion of flue gas, the solid absorbent properties are very important $[2,3]$. Lithium salts have emerged as an excellent and regenerable absorbent for the capture of carbon dioxide. Lithium salts with higher capacity and selectivity for carbon dioxide were synthesized, characterized, and tested for capturing carbon dioxide either at postcombustion or precombustion temperature [4-10]. Nakagawa and Ohashi reported that the absorption reaction rate is accelerated when lithium zirconate is doped with sodium carbonate and/or potassium carbonate. The doping produces a eutectic of molten carbonate that reduces carbon dioxide diffusion resistance [11]. Xiong et al. have studied the absorption kinetics of carbon dioxide on K-doped $\mathrm{Li}_{2} \mathrm{ZrO}_{3}$ and found that the reaction rate accelerated as the absorbent particle size reduced. The temperature effect is complex, and the appropriate temperature is about $550-590^{\circ} \mathrm{C}$ [12]. Wang et al. employed Na-doped $\mathrm{Li}_{4} \mathrm{SiO}_{4}$, prepared by hightemperature solid-state reaction, as carbon dioxide absorbent from 500 to $750^{\circ} \mathrm{C}$ [6]. The influence of sodium doping on the absorption capacity and cycle performance was studied. 
The results showed that sodium doping could improve the carbon dioxide absorption ability of lithium silicate [13-15]. Satisfactory heat tolerance, high carbon dioxide absorption capacity, and fast kinetics in multicycle operation are seldom provided with currently available absorbents.

Lithium plays an important role in capturing carbon dioxide by forming lithium carbonate. Lithium acts as promoter, titanium acts as stabilizer, and sodium acts as doping agent in the process of capturing carbon dioxide over absorbent. As carbon dioxide is acidic by nature, it is felt that incorporation of basicity in the parent matrix $\mathrm{Li}_{2} \mathrm{TiO}_{3}$ can increase the capacity and selectivity of absorbent to a higher value. Titanium dioxide has a synergy with parent matrix for higher carbon dioxide absorption capacity. Sodium doping causes an important increase of the absorption kinetic. In present study, $\mathrm{Na}$-doped $\mathrm{Li}_{2} \mathrm{TiO}_{3}$ was introduced as a suitable absorbent for carbon dioxide, and the influence of various $x$ values on the absorption capacity and cycle performance was discussed through different preliminary experiments.

\section{Materials and Methods}

2.1. Synthesis of Na-Doped $\mathrm{Li}_{2} \mathrm{TiO}_{3}$. The high temperature solid-phase process was used to prepare Na-doped $\mathrm{Li}_{2} \mathrm{TiO}_{3}$ in this work. Starting materials were $\mathrm{Li}_{2} \mathrm{CO}_{3}$ (AR, Sinopharm Chemical Reagent Co., Ltd), $\mathrm{TiO}_{2}$ (AR, Sinopharm Chemical Reagent Co., Ltd), and $\mathrm{Na}_{2} \mathrm{CO}_{3}$ (AR, Sinopharm Chemical Reagent Co., Ltd). The molar ratio of the starting materials $\left(\mathrm{Li}_{2} \mathrm{CO}_{3}: \mathrm{TiO}_{2}: \mathrm{Na}_{2} \mathrm{CO}_{3}\right)$ was $1-x: 1: x(x=0,0.01,0.03$, $0.05,0.07,0.10)$. In general, the composition of absorbent can be given as $\mathrm{Li}_{2(1-x)} \mathrm{Na}_{2 x} \mathrm{TiO}_{3}$. The $\mathrm{Li}_{2(1-x)}$ and $\mathrm{Na}_{(2 x)}$ mole ratios were varied during the synthesis of these absorbents. The six samples were named LiNa-0, LiNa-1, LiNa-3, LiNa-5, LiNa-7, and LiNa-10, respectively, according to the following values of sodium content in $\%$ mole. $\mathrm{TiO}_{2}$ were weighed, mixed with a suitable amount of ethanol, and dispersed 15 mins by the ultrasonic power. After $\mathrm{Li}_{2} \mathrm{CO}_{3}$ and $\mathrm{Na}_{2} \mathrm{CO}_{3}$ were added, the mixtures were stirred by magnetic stirrer for $2 \mathrm{~h}$ and dried at $80^{\circ} \mathrm{C}$. The precursor was calcined at $800^{\circ} \mathrm{C}$ for $20 \mathrm{~h}$. The calcined $\mathrm{Na}$-doped $\mathrm{Li}_{2} \mathrm{TiO}_{3}$ was quenched in air and ground in an agate mortar before testing.

2.2. Characterization. The crystallinity of Na-doped $\mathrm{Li}_{2} \mathrm{TiO}_{3}$ was examined using $\mathrm{X}$-ray powdered diffractometer ARL XTRA X-ray with $\mathrm{Cu} \mathrm{K}_{\alpha}$ radiation. The morphology of absorbent was observed by SEM (FEI Nano SEM430). The surface area of absorbent was measured by Micromeritics ASAP 2010 instrument. The $\mathrm{N}_{2}$ BET surface area of the absorbent was observed to be $2.39 \mathrm{~m}^{2} / \mathrm{g}$. Since the capture of carbon dioxide over absorbent depends mainly on the chemical reactions, there is no direct correlation between the surface area and the capture of carbon dioxide.

2.3. Evaluation of Absorbents. Carbon dioxide absorption on the Na-doped $\mathrm{Li}_{2} \mathrm{TiO}_{3}$ was performed using a HCT-1 thermo gravimetric analyzer (Beijing Henven Scientific Instrument Factory). About $10 \mathrm{mg} \mathrm{Na}$-doped $\mathrm{Li}_{2} \mathrm{TiO}_{3}$ powders were placed in the sample pan. The heating rate is $10^{\circ} \mathrm{C} / \mathrm{min}$,

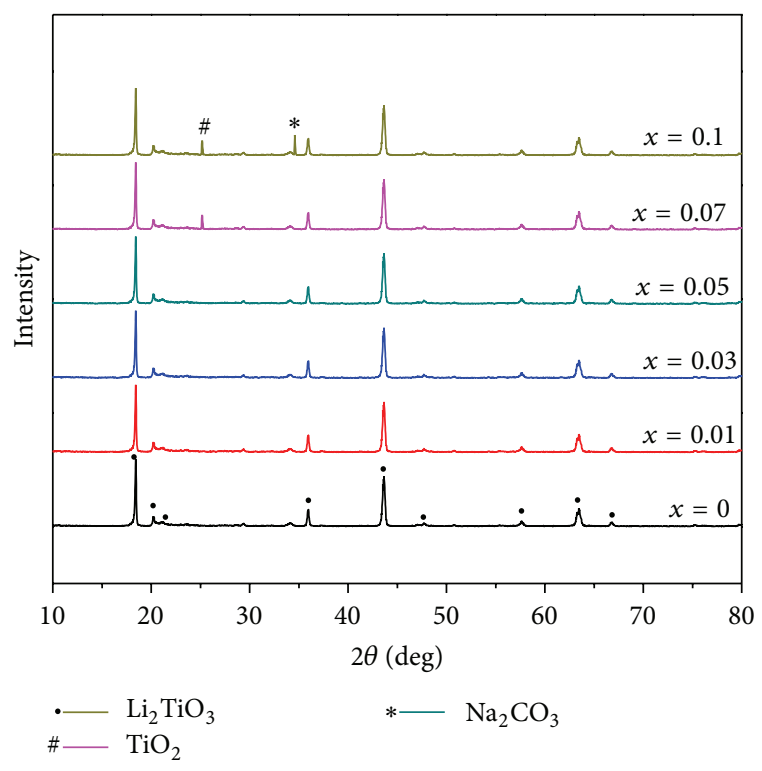

FIgURE 1: XRD patterns of Na-doped $\mathrm{Li}_{2} \mathrm{TiO}_{3}$ and $\mathrm{Li}_{2} \mathrm{TiO}_{3}$.

absorption temperature is $600^{\circ} \mathrm{C}$, absorption time span is $180 \mathrm{~min}$, and flow rate of pure carbon dioxide is $80 \mathrm{~mL} / \mathrm{min}$. Prior to absorption measurement, pure dried carbon dioxide was passed over the absorbent through thermo gravimetric analyzer in order to remove inner air.

\section{Results and Discussion}

3.1. Characterization of $\mathrm{Na}$-Doped $\mathrm{Li}_{2} \mathrm{TiO}_{3}$. The X-ray diffraction patterns of Na-doped $\mathrm{Li}_{2} \mathrm{TiO}_{3}$ and nondoped $\mathrm{Li}_{2} \mathrm{TiO}_{3}$ absorbents shown in Figure 1 reveal that $\mathrm{Li}_{2} \mathrm{TiO}_{3}$ is only monoclinic crystalline structure as the sodium doping is below $5 \% \mathrm{Na}$. However, the characteristic peaks of $\mathrm{Na}_{2} \mathrm{CO}_{3}$ and $\mathrm{TiO}_{2}$ appear as the $\mathrm{Na}$ amounts are increased through $\mathrm{Na}$ doping from sample containing $5 \%$ up to $10 \% \mathrm{Na}$ (samples LiNa-5, LiNa-7, and LiNa-10). XRD results did not show peaks associated with a $\mathrm{Na}_{2} \mathrm{TiO}_{3}$ structure clearly. It implies that a few $\mathrm{Li}$ are substituted by $\mathrm{Na}$ and a crystallographic phase is formed in $\mathrm{Li}_{2} \mathrm{TiO}_{3}$ crystals as the amount of $\mathrm{Na}$ is increased through doping. Furthermore, the crystal defects may increase absorption reactivity due to $\mathrm{Na}$ doping.

The SEM images of Na-doped $\mathrm{Li}_{2} \mathrm{TiO}_{3}$ at the magnification of 12000x are presented in Figure 2. It is observed that a greater degree of agglomeration with more irregular particle sizes appears as the $\mathrm{Na}$ amount is decreased from sample containing $10 \%$ to $1 \% \mathrm{Na}$. The morphology of sample LiNa5 exhibits a more regular uniform crystalline solid material. Moreover, the performance improvement might be attributed to the creation of lattice defects in the $\mathrm{Li}_{2} \mathrm{TiO}_{3}$ crystals by $\mathrm{Na}$ doping. In addition, the grain growth of absorbent has been accelerated by $\mathrm{Na}$ doping.

3.2. The Influence of Sodium Doping on $\mathrm{CO}_{2}$ Absorption Capacity. $\mathrm{CO}_{2}$ absorption on various $\mathrm{Na}$-doped $\mathrm{Li}_{2} \mathrm{TiO}_{3}$ at $600^{\circ} \mathrm{C}$ is presented in Figure 3. It is found that sample LiNa-3 


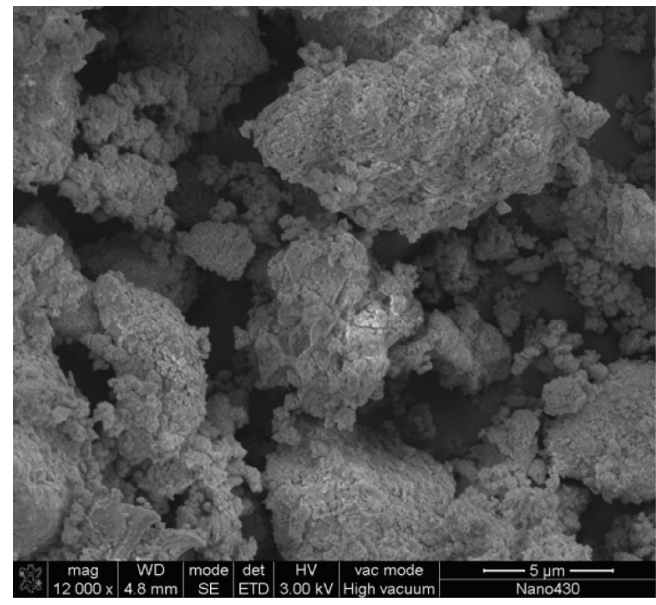

(a) $x=0.01$.

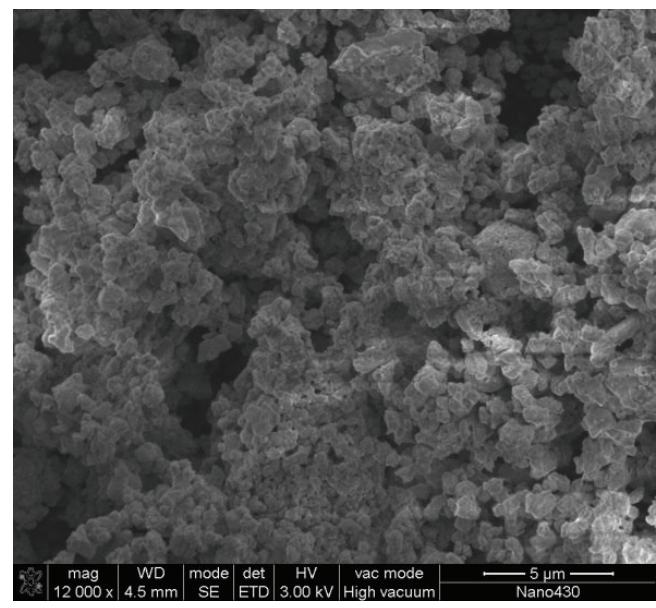

(c) $x=0.05$.

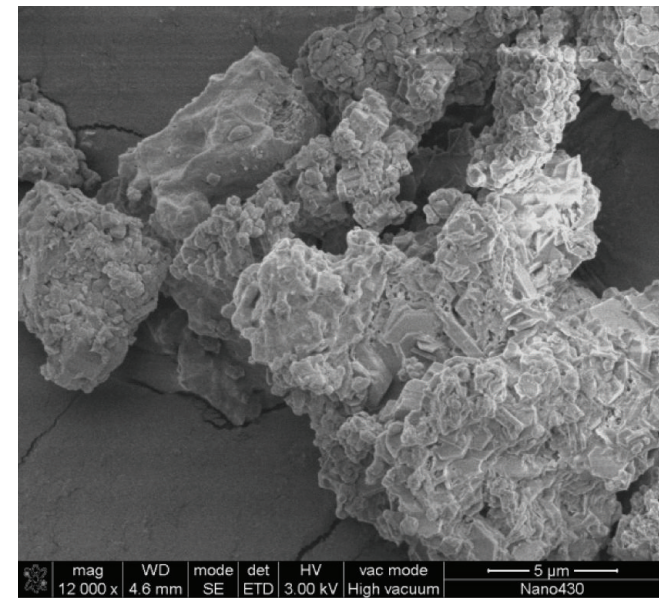

(b) $x=0.03$.

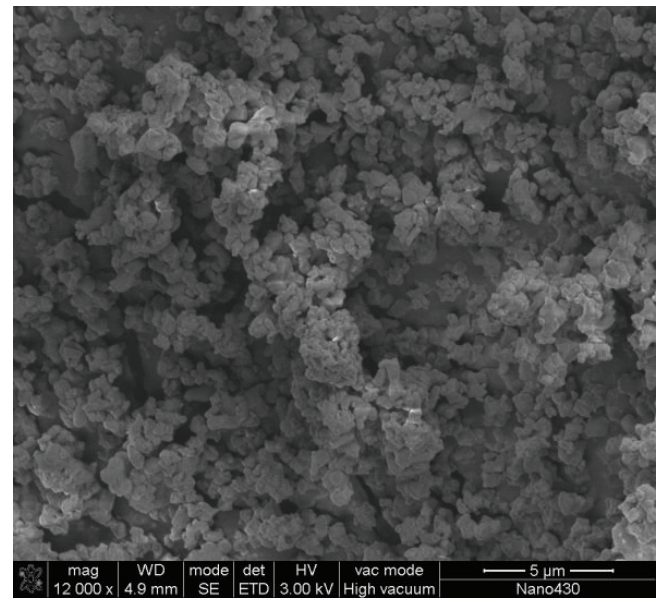

(d) $x=0.07$.

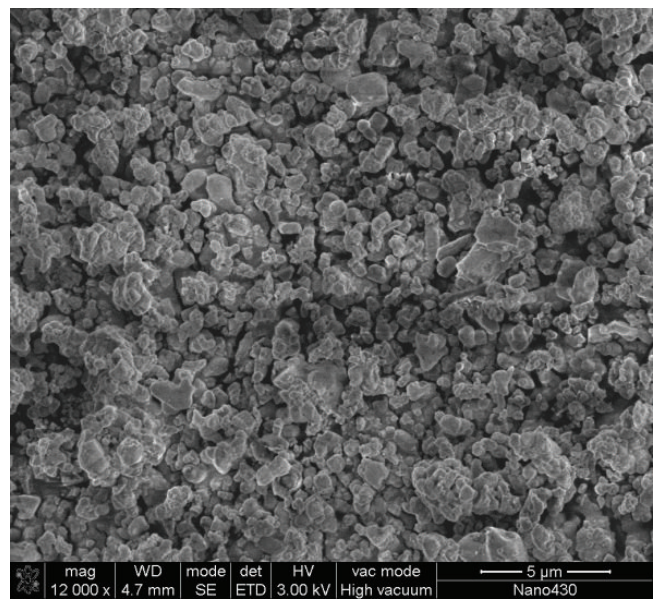

(e) $x=0.10$.

FIgURE 2: SEM images of Na-doped $\mathrm{Li}_{2} \mathrm{TiO}_{3}$. 


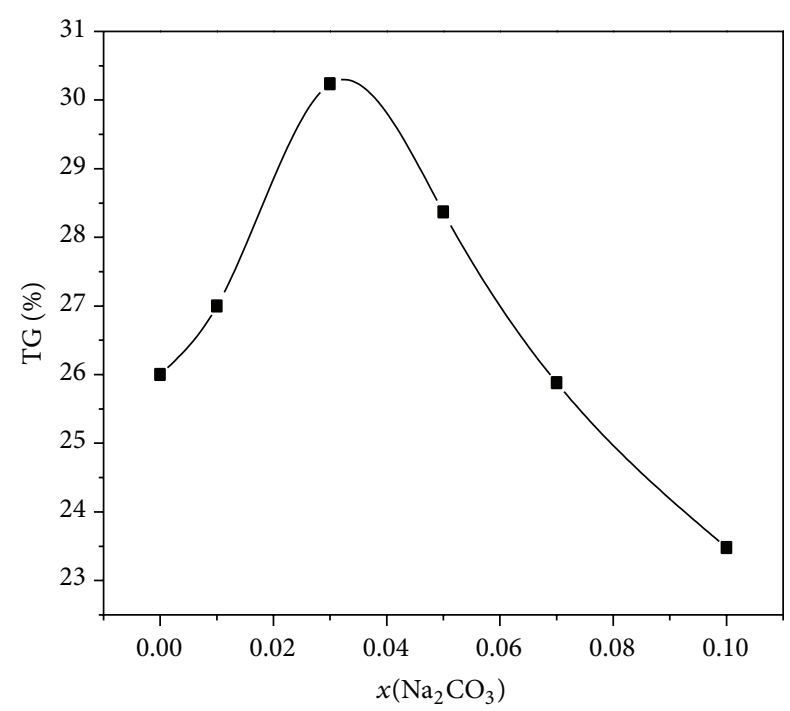

FIGURE 3: Impact of $\mathrm{Na}_{2} \mathrm{CO}_{3}$ doping on the $\mathrm{CO}_{2}$ absorption capacity by $\mathrm{Li}_{2} \mathrm{TiO}_{3}$.

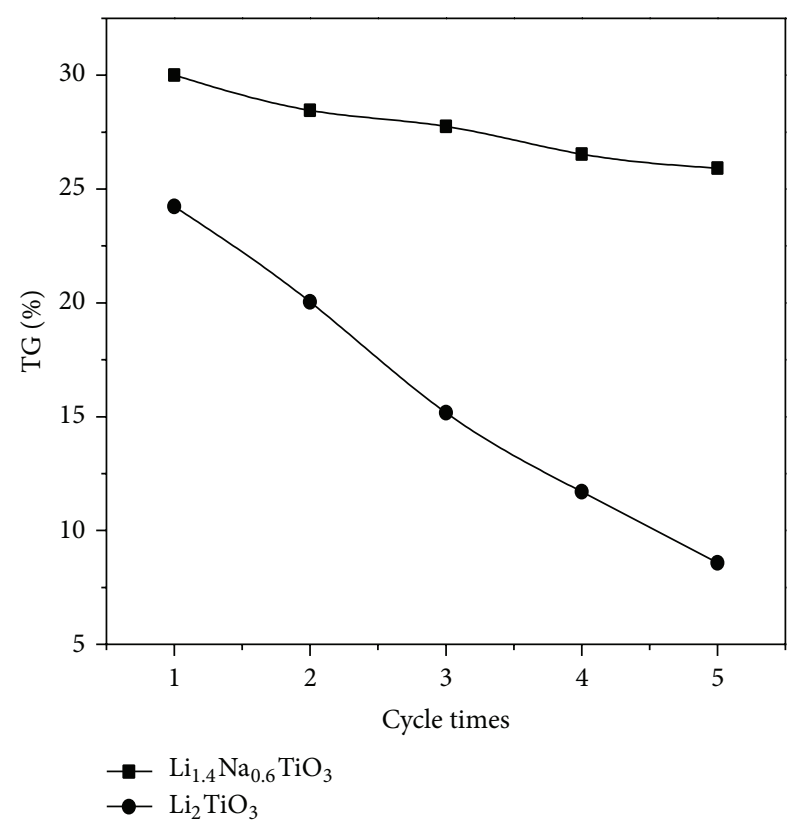

FIGURE 4: Effect of $\mathrm{Na}$ doping on cycle performance of $\mathrm{CO}_{2}$ absorption on $\mathrm{Li}_{2} \mathrm{TiO}_{3}$.

possesses the best performance and absorbs as much as 30\% (wt) of $\mathrm{CO}_{2}$. Greater than or less than $\mathrm{Na}$ amount of sample LiNa-3 will consequently be traduced in a decrease of $\mathrm{CO}_{2}$ absorption capacity. The capture of $\mathrm{CO}_{2}$ over lithium silicate $(\mathrm{Li} / \mathrm{Si}=4)$ is $1.6 \mathrm{mmol} / \mathrm{g}$ at $525^{\circ} \mathrm{C}$ [16]. As much as $(25 \pm 0.6) \%$ (wt) of $\mathrm{CO}_{2}$ was absorbed by lithium zirconate [17].

3.3. The Influence of Sodium Doping on $\mathrm{CO}_{2}$ Absorption Cycle Performance. $\mathrm{CO}_{2}$ absorption cycle performances of pure nondoped $\mathrm{Li}_{2} \mathrm{TiO}_{3}$ and sample $\mathrm{LiNa}-3$ are presented in Figure 4. As shown, $\mathrm{CO}_{2}$ absorption capacity of two samples
TABLE 1: Relative permeability during absorption process at 500 $600^{\circ} \mathrm{C}$.

\begin{tabular}{lcc}
\hline Item & ${\mathrm{Pure} \mathrm{Li}_{2} \mathrm{TiO}_{3}}$ & $\mathrm{Na}$-doped $\mathrm{Li}_{2} \mathrm{TiO}_{3}$ \\
\hline $\mathrm{TiO}_{2}$ layer state & Solid & Solid \\
$\mathrm{O}^{2-}$ permeability & $\sim 10^{-12} \mathrm{~cm}^{2} / \mathrm{m}$ & $\sim 10^{-12} \mathrm{~cm}^{2} / \mathrm{m}$ \\
$\mathrm{Li}_{2} \mathrm{CO}_{3}$ layer state & Solid & Liquid \\
$\mathrm{CO}_{2}$ permeability & $\sim 10^{-14} \mathrm{~cm}^{2} / \mathrm{m}$ & $\sim 10^{-8} \mathrm{~cm}^{2} / \mathrm{m}$ \\
Rate-determining step & $\mathrm{CO}_{2}$ diffusion & $\mathrm{O}^{2-}$ diffusion \\
\hline
\end{tabular}

both decrease, cycle performance of Na-doped $\mathrm{Li}_{2} \mathrm{TiO}_{3}$ falls $14.28 \%$ after 5 times cycle, but that of pure non doped $\mathrm{Li}_{2} \mathrm{TiO}_{3}$ falls $67.03 \%$ after the same times cycle. So the cycle performance increases obviously by $\mathrm{Na}$ doping. This behavior can be explained in terms of a newly formed structure after Na doping process [18].

3.4. The Double-Shell Mechanism of $\mathrm{CO}_{2}$ Absorption on $\mathrm{Na}$ Doped $\mathrm{Li}_{2} \mathrm{TiO}_{3}$. Xiao et al. investigated the double-shell mechanism of $\mathrm{CO}_{2}$ absorption on $\mathrm{Li}_{2} \mathrm{ZrO}_{3}$ at high temperature [15]. The absorption process of $\mathrm{CO}_{2}$ on Na-doped $\mathrm{Li}_{2} \mathrm{TiO}_{3}$ particles could properly be described by double-shell mechanism. Although eutectic molten carbonate composed of $\mathrm{Li}_{2} \mathrm{CO}_{3}$ and $\mathrm{Na}_{2} \mathrm{CO}_{3}$ on the outer layer cannot react with $\mathrm{CO}_{2}$, molten carbonate facilitates the transfer of gaseous $\mathrm{CO}_{2}$ into the inner unreacted layer. Meantime, $\mathrm{O}^{2-}$ and $\mathrm{Li}^{+}$ released by $\mathrm{Li}_{2} \mathrm{TiO}_{3}$ reach inner layer through $\mathrm{TiO}_{2}$ layer. Then $\mathrm{O}^{2-}, \mathrm{Li}^{+}$, and $\mathrm{CO}_{2}$ encounter and react, forming $\mathrm{Li}_{2} \mathrm{CO}_{3}$ among inner layer. As this process proceeds, $\mathrm{TiO}_{2}$ layer and molten salt layer are thickened, diffusion time of $\mathrm{O}^{2-}, \mathrm{Li}^{+}$, and $\mathrm{CO}_{2}$ is lengthened, and absorption process is slowed down. The relative permeability of $\mathrm{O}^{2-}$ and $\mathrm{CO}_{2}$ in absorption process at $500-600^{\circ} \mathrm{C}$ was listed in Table 1 [19].

From Table 1, the rate-determining steps of $\mathrm{CO}_{2}$ absorption on pure $\mathrm{Li}_{2} \mathrm{TiO}_{3}$ and $\mathrm{Na}$-doped $\mathrm{Li}_{2} \mathrm{TiO}_{3}$ are $\mathrm{CO}_{2}$ diffusion rate and $\mathrm{O}^{2-}$ diffusion rate, respectively. $\mathrm{O}^{2-}$ diffusion rate is faster than $\mathrm{CO}_{2}$. So absorption rate of $\mathrm{CO}_{2}$ on $\mathrm{Na}$ doped $\mathrm{Li}_{2} \mathrm{TiO}_{3}$ is faster. $\mathrm{CO}_{2}$ absorption process on $\mathrm{Na}$ doped $\mathrm{Li}_{2} \mathrm{TiO}_{3}$ was qualitatively described well by doubleshell mechanism.

\section{Conclusions}

(1) $\mathrm{CO}_{2}$ capacity on Na-doped $\mathrm{Li}_{2} \mathrm{TiO}_{3}$ can be improved by sodium doping. There is the maximum capacity when $\mathrm{n}\left(\mathrm{TiO}_{2}\right): \mathrm{n}\left(\mathrm{Li}_{2} \mathrm{CO}_{3}\right): \mathrm{n}\left(\mathrm{Na}_{2} \mathrm{CO}_{3}\right)=1: 0.97$ : 0.03 .

(2) XRD patterns show that sodium doping led to crystal defect that could make absorption reactivity increase. From SEM images, it was speculated that sodium doping does not change morphology, but it makes particles looser and fracture phenomenon occurred.

(3) $\mathrm{CO}_{2}$ absorption cycle performance decay dropped to $14.28 \%$. Compared with the $67.03 \%$ of pure $\mathrm{Li}_{2} \mathrm{TiO}_{3}$, it has been greatly increased. 
(4) The double-shell mechanism described $\mathrm{CO}_{2}$ absorption process on $\mathrm{Na}$-doped $\mathrm{Li}_{2} \mathrm{TiO}_{3}$; sodium presence changing rate-determining step of the process is the main reason of performance improved.

\section{Conflict of Interests}

The authors declare that they have no conflict of interests regarding the publication of this paper.

\section{Acknowledgments}

This study was financially supported by Natural Science Foundation of China (Grant: 11375043) and Jiangxi Province Science and Technology Support Program (Grant: 20112BBG70006).

\section{References}

[1] H. Yang, Z. Xu, M. Fan et al., "Progress in carbon dioxide separation and capture: a review," Journal of Environmental Sciences, vol. 20, no. 1, pp. 14-27, 2008.

[2] M. Kato, S. Yoshikawa, and K. Nakagawa, "Carbon dioxide absorption by lithium orthosilicate in a wide range of temperature and carbon dioxide concentrations," Journal of Materials Science Letters, vol. 21, no. 6, pp. 485-487, 2002.

[3] M. Mohammadi, P. Lahijani, and A. R. Mohamed, "Refractory dopant-incorporated $\mathrm{CaO}$ from waste eggshell as sustainable sorbent for $\mathrm{CO}_{2}$ capture: experimental and kinetic studies.," Chemical Engineering Journal, vol. 243, pp. 455-464, 2014.

[4] R. Xiong, J.-I. Ida, and Y. S. Lin, "Kinetics of carbon dioxide sorption on potassium-doped lithium zirconate," Chemical Engineering Science, vol. 58, no. 19, pp. 4377-4385, 2003.

[5] A. Iwan, H. Stephenson, W. C. Ketchie, and A. A. Lapkin, "High temperature sequestration of $\mathrm{CO}_{2}$ using lithium zirconates," Chemical Engineering Journal, vol. 146, no. 2, pp. 249-258, 2009.

[6] Y.-J. Wang, Q. Lu, and K.-H. Dai, "Effect of Na-doping on $\mathrm{CO}_{2}$ absorption of $\mathrm{Li}_{4} \mathrm{SiO}_{4}$," Acta Physico: Chimica Sinica, vol. 22, no. 7, pp. 860-863, 2006.

[7] V. S. Derevschikov, A. I. Lysikov, and A. G. Okunev, "Sorption properties of lithium carbonate doped $\mathrm{CaO}$ and its performance in sorption enhanced methane reforming," Chemical Engineering Science, vol. 66, no. 13, pp. 3030-3038, 2011.

[8] R. T. Xiong, Novel inorganic sorbent for high temperature carbon dioxide separation [dissertation], The University of Cincinnati, Cincinnati, Ohio, USA, 2003.

[9] J.-I. Ida, R. Xiong, and Y. S. Lin, "Synthesis and $\mathrm{CO}_{2}$ sorption properties of pure and modified lithium zirconate," Separation and Purification Technology, vol. 36, no. 1, pp. 41-51, 2004.

[10] J.-I. Ida and Y. S. Lin, "Mechanism of high-temperature $\mathrm{CO}_{2}$ sorption on lithium zirconate," Environmental Science and Technology, vol. 37, no. 9, pp. 1999-2004, 2003.

[11] K. Nakagawa and T. Ohashi, "A novel method of $\mathrm{CO}_{2}$ capture from high temperature gases," Journal of the Electrochemical Society, vol. 145, no. 4, pp. 1344-1346, 1998.

[12] R. Xiong, J.-I. Ida, and Y. S. Lin, "Kinetics of carbon dioxide sorption on potassium-doped lithium zirconate," Chemical Engineering Science, vol. 58, no. 19, pp. 4377-4385, 2003.

[13] P. Claes, B. Thirion, and J. Glibert, "solubility of $\mathrm{CO}_{2}$ in the molten $\mathrm{NA}_{2} \mathrm{CO}_{3}-\mathrm{K}_{2} \mathrm{CO}_{3}(42 \mathrm{~mol} \%)$ eutectic mixture at $800^{\circ} \mathrm{C}$," Electrochimica Acta, vol. 41, no. 1, pp. 141-146, 1996.
[14] P. Spedding and R. Mills, "Tracer diffusion measurements in mixtures of molten alkali carbonates," Journal of the Electrochemical Society, vol. 113, no. 6, pp. 599-603, 1966.

[15] Q. Xiao, X. Tang, Y. Liu, Y. Zhong, and W. Zhu, "Citrate route to prepare $\mathrm{K}$-doped $\mathrm{Li}_{2} \mathrm{ZrO}_{3}$ sorbents with excellent $\mathrm{CO}_{2}$ capture properties," Chemical Engineering Journal, vol. 174, no. 1, pp. 231-235, 2011.

[16] P. V. Korake and A. G. Gaikwad, "Capture of carbon dioxide over porous solid adsorbents lithium silicate, lithium aluminate and magnesium aluminate at pre-combustion temperatures," Frontiers of Chemical Engineering in China, vol. 5, no. 2, pp. 215226, 2011.

[17] Y. Wang, L. Qi, K. Du, and L. Wen, "Effect of doping K element on properties of lithium zirconate as $\mathrm{CO}_{2}$-absorbent," Acta Scientiarum Naturalium Universitatis Pekinensis, vol. 41, no. 4, pp. 501-505, 2005 (Chinese).

[18] J. A. Thote, R. V. Chatti, K. S. Iyer et al., "N-doped mesoporous alumina for adsorption of carbon dioxide," Journal of Environmental Sciences, vol. 24, no. 11, pp. 1979-1984, 2012.

[19] V. Guzmán-Velderrain, D. Delgado-Vigil, V. Collins-Martínez, and A. L. Ortiz, "Synthesis, characterization and evaluation of sodiumdoped lithium zirconate as a high temperature $\mathrm{CO}_{2}$ absorbent," Journal of New Materials for Electrochemical Systems, vol. 11, no. 2, pp. 131-136, 2008. 

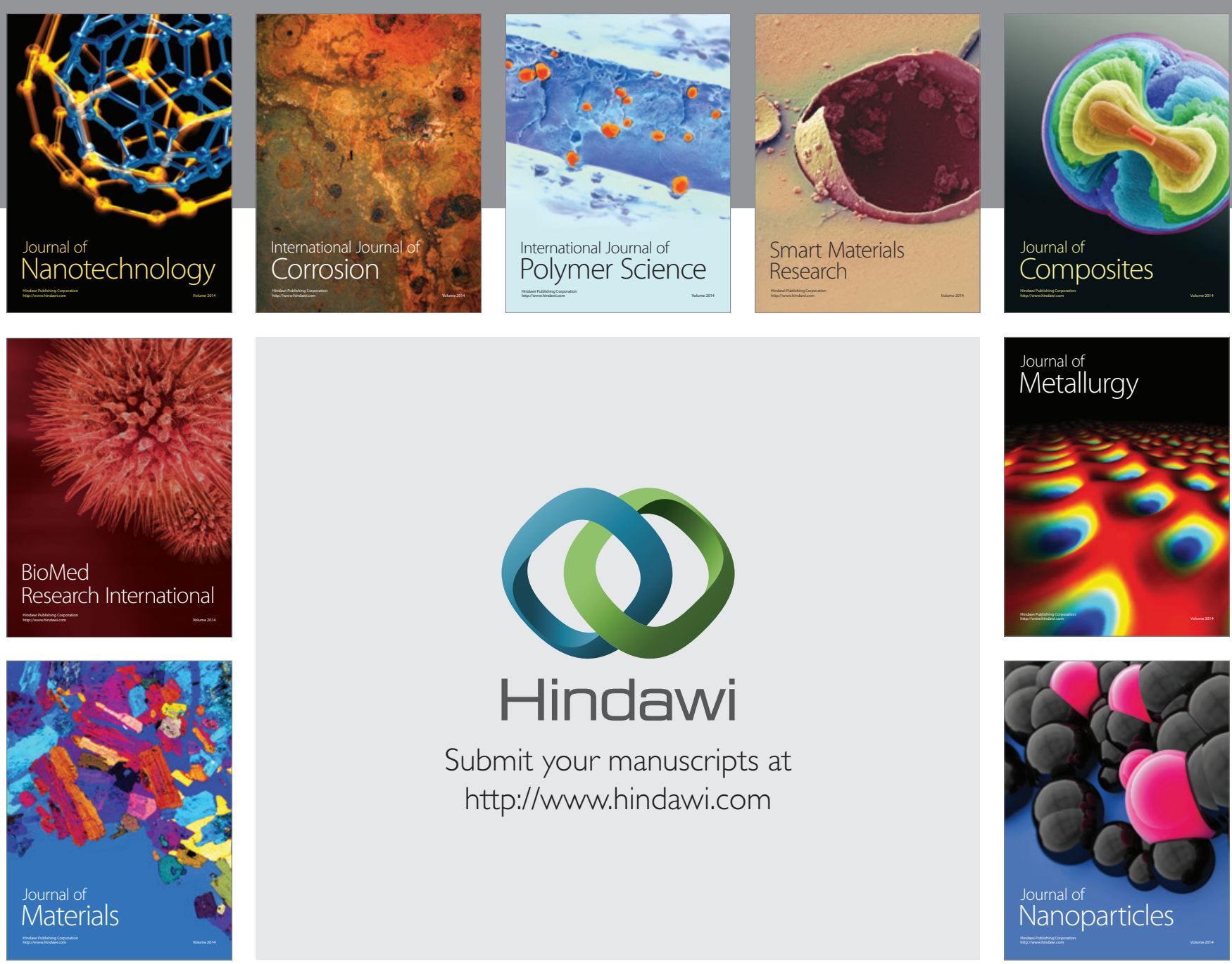

Submit your manuscripts at http://www.hindawi.com
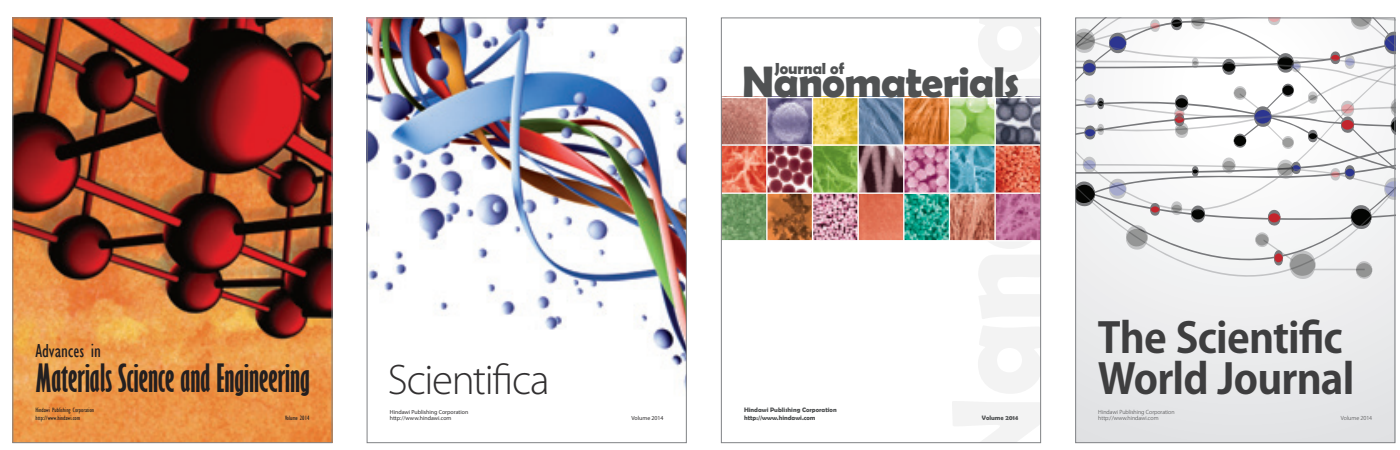

\section{The Scientific World Journal}
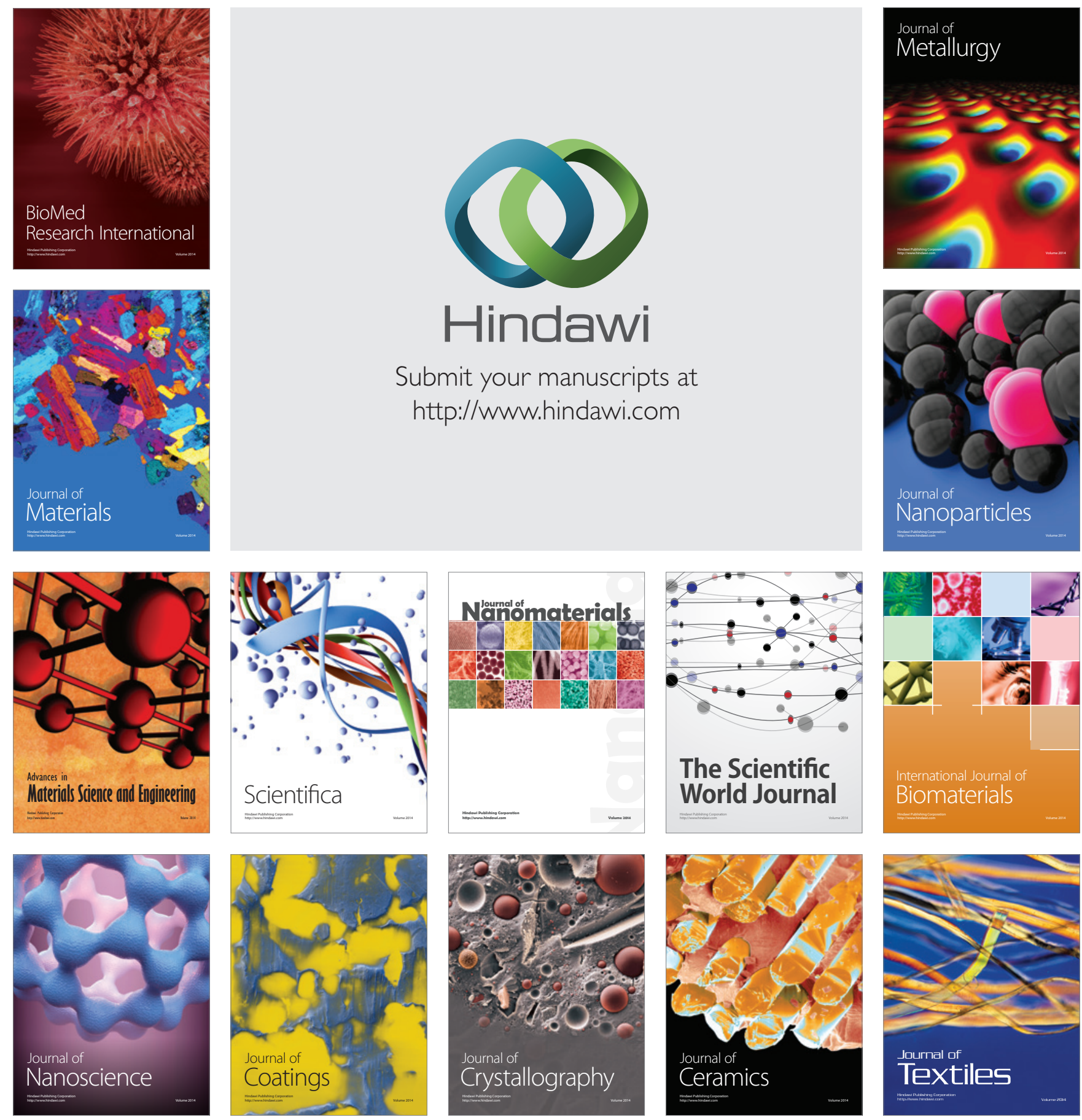